\section{EMBRYRIDDLE}

Aeronautical University

SCHOLARLY COMMONS
Journal of Aviation/Aerospace

Education \& Research

Volume 30

Number 1 JAAER 2021

Article 5

2021

\title{
Analysis on the Negative Emotional, Physiological, and Cognitive Responses Elicited from of the Activation of a Stall Alarm
}

Travis J. Whittemore

Embry-Riddle Aeronautical University,whittemt@erau.edu

Sabrina Woods

Federal Aviation Administration, sportin2u76@gmail.com

Follow this and additional works at: https://commons.erau.edu/jaaer

Part of the Science and Technology Studies Commons

\section{Scholarly Commons Citation}

Whittemore, T. J., \& Woods, S. (2021). Analysis on the Negative Emotional, Physiological, and Cognitive Responses Elicited from of the Activation of a Stall Alarm. Journal of Aviation/Aerospace Education \& Research, 30(1). https://doi.org/10.15394/jaaer.2021.1881

This Article is brought to you for free and open access by the Journals at Scholarly Commons. It has been accepted for inclusion in Journal of Aviation/Aerospace Education \& Research by an authorized administrator of Scholarly Commons. For more information, please contact commons@erau.edu. 
An aerodynamic stall occurs when the critical angle of attack (AOA) of an aircraft is exceeded, causing reduced lift (Anderson, 1999). Failing to identify the situation and correctly apply an appropriate physical response in a timely manner can lead to the inability of an aircraft to sustain flight. To warn pilots of an impending or fully developed stall, many aircraft have safety devices installed to provide visual, aural, and/or kinesthetic (haptic) indicators of a potentially unsafe situation. One form of stall warning is a stick shaker - a mechanical device that rapidly vibrates the pilot's controls to alert the aircrew to an impending stall via haptic stimulus. Another common form is an aural alert system, and often the two are used in conjunction with one another.

In 2017, the Federal Aviation Administration (FAA) published Advisory Circular 120111, which discussed requirements for Upset Recovery Training. One of the conditions that typically describe an upset is a pitch attitude of more than 25 degrees nose up, which is also one of the characteristics of a developing stall. The FAA specifically mentions how startle or surprise can adversely impact recognition and recovery (FAA, 2017). Goleman (1995) refers to the phenomenon as limbic hijack and defines it as the disruptive emotional and cognitive response that occurs as a result of stimulus (note: limbic hijack is disproportionate in severity to the actual stimulus). Colloquially known as a fight or flight trigger, amygdala or limbic hijack can cause a person to freeze in place or can disrupt cognitive function (Martin, Murray, \& Bates, 2012). A person experiencing this hijack cannot process available information or is unable to introduce corrective action in order to avert the original causal factor (Goleman, 1995). Stick shakers, if rapidly activated, can potentially produce unintended, negative reactions. While studies have suggested the activation of an aural alarm might result in amygdala hijack, little research has been conducted on how a stick shaker might create a similar disruption. 
The stick shaker has the potential to be a startling and violent form of stall warning. Well-meaning but intense warnings from the system could inadvertently produce a fight, freeze, or flight response from an aircrew. This article discusses how the stick shaker might cause a physiological and cognitive disruption to the recipient, identifies the risks associated with these types of systems, and suggest solutions to reduce negative consequences.

\section{Amygdala Hijack}

According to Goleman (1995), when the brain receives information, stimulus travels to two places in the brain from the thalamus: the amygdala and the neocortex. The neocortex is the thinking part of the brain, while the amygdala processes physiological response and fight or flight information. If stimulus is sent to the amygdala, it can hijack the rational part of the brain due to faster processing speeds (Goleman, 1995). When the amygdala perceives a threat, it forces the brain to command unexpected or unintended responses including irrational and destructive actions (Freedman, 2009).

"If the emotional brain does not like what it is seeing, it will declare an emotional emergency, an amygdala hijack" (Goleman, 1998, p. 20). Most individuals can only be effective when both the emotional and thinking brain work together (Goleman, 1998). In another definition of amygdala hijack: individuals are hardwired to instinctively protect themselves from harm — when specific threats present themselves, neurochemicals are released "that paralyze the brain's ability to think and activate our instincts for fight, flight, freeze, and appease" (Glaser \& Tartell, 2014, p. 63). Any perception of threat or distrust forces the amygdala to respond, thus locking down any response capabilities. Amygdala hijack can be found in many examples but is most likely to occur when individuals are placed in one of seven universal threats: tone threat, 
hurt threat, risk \& punishment threat, exclusion threat, anger threat, territory threat, and status threat (Glaser \& Tartell, 2014).

\section{Stall Warning Devices}

It is easy for pilots to inadvertently fly themselves into the stall region known as Controlled Flight into Stall (CFIS) (Sherry \& Mauro, 2014). Due to the ease of entering the stall region, stall warning devices are critical for situation awareness and are designed to immediately grab the attention of the pilot, as rectifying the stall should become the priority of the aircrew. A warning must accomplish certain human-reactions to be effective (Laughery \& Wogalter, 2006). The warning must capture attention and be noticed, but just as important, the warning must provide desired information. Once the warning has effectively provided information to the person of interest, the warning should help influence behavior, not prevent undesired states. In some aircraft, the attention-capture function of a stall consists of shrill squeals and the shaking of the flight controls. The warning then provides information by annunciating the word, STALL, and lastly, the warning continues until the stall condition has been satisfied. If the warning system is too violent in the capture attention phase, it is possible for the system to cause cognitive disruption that will prevent the pilot from advancing to the provide information stage.

\section{Aviation Perspective}

Applying Glaser and Tartell's (2014) theories, there are multiple situations where an individual can exhibit a marked decrease in cognitive function or experience an amygdala/limbic hijack, with hurt threat the most likely universal threat for a stall warning. The presence of a stall warning indicates the aircraft, along with all the passenger and cargo aboard, are in immediate and grave danger. The reaction to the shaker itself can come as a surprise to the pilot particularly if the pilot has failed to perceive any of the information contributing to the stall beforehand. 
There is another potential reason for the hijack, however. In the event pride is a driving factor, it may be possible for status threat or exclusion threat to be the overall cause of the hijack. In a stall, an experienced pilot may not want to feel the embarrassment of having flown into a situation that caused activation of the stick shaker and could feel shame, while at the same time, a lesser experienced co-pilot who enters the stall region may have feelings of inadequacy or inability to perform to the same level as the captain. Regardless, it is important to note that the high-frequency vibrations or the loud stall warning horn may not be the only cause of the amygdala hijack; a cultural situation could also be driving the outcome.

\section{Situation Awareness-Oriented Design Analysis}

The effects of startle on pilot-reactions and decision-making ability has been well documented on aviation accidents. On June 1, 2009, Air France Flight 447 entered a fullydeveloped, sustained stall from which none of the flight crew were able to execute the proper reactions necessary to recover. According to Lacagnina (2012), among the causal factors for the accident were training deficiencies, lack of situation awareness (SA), ineffective crew resource management, and, what could be considered a catalyst, the startle effect.

Research has shown that not only does a startle activate the fight, freeze, or flight response in the recipient, it can also badly impair or even completely disrupt cognitive ability and psychomotor skills for up to 30 seconds or more (Martin et al., 2012). During this time, the disruption typically proceeds along one of three paths: 1) the initial disruption abates into conflict resolution; 2) the disruption leads to the wrong decision-making path; or 3) the disruption causes the person to freeze in place, also known as the fear-potentiated startle (Martin et al., 2012). There exists a cognitive sequence for alerts—perceive, diagnose, decision selection, and action (Pinet, 2012); these four steps closely mimic Endsley and Jones' (2004) Levels 1 
through 3 situational awareness sequence of perception, comprehension, and projection. However, even with a properly trained operator, these sequences can propagate dysfunction if the alert system does not adequately provide timely, relevant data. During the Air France mishap sequence, the aural stall warning systems onboard the A330 sounded 75 times in an attempt to alert the crew to the most immediate problem at hand (Bureau d'Enquêtes et d'Analyses [BEA], 2012). Despite the number of attempts, there was no verbal acknowledgement to the warning.

In a similar mishap that developed much more rapidly, Colgan Air Flight 3407, while en route to Buffalo, New York, experienced a nose-high, low-airspeed attitude which caused the stick shaker warning system to activate and the auto-pilot to disengage. Startled, the crew proceeded down the wrong decision-making path; ultimately taking the aircraft from an impeding stall to a fully developed stall from which they were unable to recover (Geiselman, Johnson, \& Buck, 2013).

\section{Last, Ethiopian Airlines Flight 302 departed Addis Ababa Bole International Airport on} March 10, 2019 headed for Nairobi. Shortly after take-off, a deviation between the left and right angle-of-attack sensors, and the left and right airspeed, altitude, and flight director bars were recorded and the aircraft entered a series of abrupt nose-down pitches (Aircraft Accident Investigation Bureau [AAIB], 2020). At the same time, the stick shaker on the Boeing 737 aircraft activated and remained activated during the entire six-minute sequence resulting in a significant physical and cognitive demand on the captain (the pilot flying) and impeding effective communication between the captain and the first officer. While the aircraft was not actually in a developed stall as with the previous two examples, the additional excessive cognitive loads the stick shaker placed on the crew was likely highly disruptive and distracting in 
nature. The crew of Ethiopian Airlines were unable to successfully bring their aircraft back under control and they crashed approximately 37 miles southeast of Addis Ababa.

A well-designed alarm system should call the operators' attention to the most pertinent information required to seek conflict resolution without over-saturating the user to the point of work overload (Endsley \& Jones, 2004; Curtis, Jentsch, \& Wise, 2010) or overstimulating the user to the point of startle (Martin et al., 2012). A design goal for any warning system should be to assist the operator in maintaining situational awareness during flight and while simultaneously avoiding an aerodynamic stall.

Geiselman et al. (2013) state that automation and automated warning systems should incorporate a context-awareness design solution. They believe that a user-centric system should be able to communicate its limitations effectively and provide prompts that guide the operator in the appropriate direction at the appropriate time (Geiselman et al., 2013). Situation awareness (SA) is a large part of establishing this context-aware design, and therefore, the first goal in the design process should be to maintain SA. SA supports the ability to extract information to use in the effective decision-making processes (Wickens, 2000). Endsley and Jones (2004) developed a series of situation awareness-oriented design (SAOD) principles that are meant to minimize disruption to ongoing activities, present information directly to user in order to support comprehension and provide projection support. Applying the following principles can help lead towards a more proactive stall alert system:

- Principle 2 - present information directly to support comprehension

- Principle 25 - don't make people reliant on alarms - provide projection support

- Principle 31 - minimize alarm disruption to ongoing activities 


\section{Principle 2: Present Information Directly to Support Comprehension}

Principle 2-present information directly to support comprehension, is a principle relating to the amount of information and the way it shall be relayed to the operator (Endsley \& Jones, 2004). Due to a human's limited working memory and attention, it is important to produce easy-to-understand and concise information to the operator. As an aircraft approaches a stall, it would not be beneficial to have a flashing number indicating the AOA of the aircraft in degrees. The visual indicator would draw the operator's attention away from the overall assessment of the aircraft, environment, and array and cause him or her to focus on the indicator instead of mitigating the situation.

A better warning simplifies the process by allowing the pilot to understand the problem immediately (Endsley \& Jones, 2004). For example, in many current airframes, as the airspeed approaches the current aerodynamic stall speed, the stall warning horn annunciates, and the stick shaker activates ("Stall Warning”, 2014). The aural indication of STALL should tell the operator exactly what the situation is if he or she is able to receive that information. Likewise, the haptic warning of the stick shaker indicates where the operator should apply physical force in order to correct the situation. The aural and physical warnings provide information and continue until the situation is remedied. The information is presented directly to the pilot, without the need to organize or decipher.

\section{Principle 25: Don’t Make People Reliant on Alarms-Provide Projection Support}

Principle 25-don't make people reliant on alarms-provide projection support, encompasses the idea of giving pilots situational awareness in order to recognize a potential issue before a problem manifests. Warnings require operators have an understanding of the alarm and why an alarm is sounding (Endsley \& Jones, 2004). A potentially better solution to a simple 
awareness warning is one which provides operators with information to be proactive- -for example, terrain-following software no longer only alerts the pilot to impending terrain, but often includes proactive instructions such as PULL UP.

The Traffic Collision Avoidance System (TCAS) is another example of software that has evolved beyond simply alerting pilots to impending situations. The software actively instructs pilots not only to pitch up or down but gives very specific visual information to provide the optimal rate solution for escaping the threat. Terrain warnings and TCAS are examples of proactive alarms that provide projection support to aviators. Few stall warning systems provide proactive projection support.

Stall warning systems only provide information that a stall is either impending or already in progress. One way to provide projection support is with trend data (Endsley \& Jones, 2004). Because stalls can occur for multiple reasons, it may be difficult to accurately provide projection support for every situation. However, trends can provide stall systems with decision-making support including audio warnings: STALL, ADD POWER or STALL, PUSH DOWN instead of simply STALL. A stall situation is the result of the critical AOA being exceeded and while resolution typically requires the aircraft to gain speed through full advancement of the thrust controls and by lowering AOA, there could be select situations where these options are not desired and sound reasoning would still have to be applied.

\section{Principle 31: Minimize Alarm Disruption to Ongoing Activities}

Principle 31 -minimize alarm disruptions to ongoing activities, highlights that an alarm in a system that is more likely to register false alarms, or alarms for less immediate situations, are more likely to be disabled and can interfere with routine flight. Conversely, the more immediate the situation is, and the rarer the event is for which the alarm is sounding, the more 
invasive the alarm should be. The stall warning system should be activated immediately and systematically when the aircraft exceeds a predetermined angle of attack. The warning system should continuously alarm and provide warning inputs until the aircraft no longer exceeds predetermined AOA.

It would be detrimental for the pilot to have the ability to turn off the stall system, or even to be able to silence the aural horn (Endsley \& Jones, 2004). As the aircraft approaches an impending stall, the operator should focus all primary attention on stall-recovery procedures. The stall warning system should be loud and forceful enough to command the attention of the pilots; however, the system should not be so loud or aggressive as to create an amygdala hijack or prevent communication between pilots.

It is important the warning system ensures the pilots are aware of the situation yet balances against the disruption of the actual warning response (Endsley \& Jones, 2004). The stall warning should forcefully capture the attention of the operator and guide him or her to the area that needs attention rather than startle the individual into undesirable performance. The stall warning should continue to annunciate and only lessen as the risk to the aircraft is mitigated. While many alarms require minimum disruption to the ongoing activities, the stall warning horn could be the exception as it is actually necessary for the pilot to focus almost all energy into preventing a stall when the warning is active.

It is important for operators to distinguish multiple alarms and warnings through vast amounts of display and warning data, without specific warnings being summarily dismissed entirely. When a stall warning occurs, the alarm is often violent, loud, and forceful. The alarm is designed to capture full attention of the pilot and reinforce the imminent danger. It is possible for systems such as the stall warning to actually diminish global SA (Endsley \& Jones, 2004). While 
the system attempts to project awareness of the impending stall, overall situation awareness may be completely lost during the period of recovery. The potential becomes high that other significant factors might be missed during this attention capture phase. This idea ties into the theory that a startled pilot may temporarily lose cognitive and fine-psychomotor ability to maintain effective decision-making (Martin et al., 2012). In its attempt to direct a pilot to the most immediate situation, any form of global SA might be temporarily lost.

The counterargument is that an approaching stall is an immediate and ultimately deadly state and therefore all awareness should be placed directly on an impending danger. There must be a balance in the creation of a stall warning system that enhances situation awareness for the operators and lowers potential for startle induced limbic hijack, while still appropriately emphasizing the importance of such a high-level threat. A stall warning system that supports the recovery of global SA is the most ideal because it facilitates effective decision-making (Endsley \& Jones, 2004; Wickens, 2000). For example, one potential idea is in an automated system where the auto-pilot and auto-throttles physically correct the attitude and airspeed of the aircraft in order to mitigate stall parameters. The action would be in conjunction with an aural warning of STALL-INCREASE THRUST, or STALL—REDUCE AOA. The warning is intended to provide the operator the reasoning for the action and guide him or her to the circumstances for which the correction was warranted - in this case, excessive AOA.

\section{Situation-Awareness Measurement Assessments}

Due to the increasing use and efficiency of automated flight management systems, the human in the interface has largely been relegated to the role of observer (Breton \& Bossé, 2002). When conflict is introduced in the form of an emergency, however, the person in the system must divert his or her attention from maintaining an active monitor and scan to becoming the 
problem-solver. The cognitive load changes when the operator must begin dealing with the situation and subsequently applying the decision-making and physical inputs required to mitigate the problem to a satisfactory outcome.

In high-stress, highly dynamic situations, valuable information is often left disregarded or underutilized because the human brain simply cannot react fast enough (Berka et al., 2007). In addition, if the individual is startled, neurochemicals are released "that paralyze the brain's ability to think and activate our instincts for fight, flight, freeze, and appease" (Glaser \& Tartell, 2014, p. 63). In this state of amygdala hijack, the person can command unexpected or unintended responses including irrational and destructive inputs that are contrary to the safe mitigation of the problem (Freedman, 2009). A design's ability to help develop or maintain situation awareness (SA) must be assessed in order to determine if the proposed design is the most correct course of action.

\section{Conclusion}

The role of any aircraft warning system is to help notify and prioritize the issues for the pilot (Ensdley \& Jones, 2004). Any disruption to spatial awareness, systems awareness, or task awareness results in a disruption in the ability to execute safe flight (Wickens, 2002). Thus, cognitive errors are ultimately the result of a deficiency in flight monitoring (Muthard \& Wickens, 2002) as well as an involuntary response to startle (Martin et al., 2012). Subject matter experts indicate the primary goal for any pilot is to maintain situation awareness, execute effective decision-making, and to avoid aircraft stall. However, to affect the proper outcome, stall warning systems must be designed with SA in mind.

Designing a stall warning system is a challenging process. The warning system must adequately warn the pilot without causing a cognitive disruption by placing the pilot into 
amygdala hijack. Very little research has been completed connecting amygdala hijack to stall warning systems; therefore, further research will be extremely valuable. A properly designed system must help an individual identify and prioritize the issues without hindering the process itself. The alarm has the extra burden of maintaining a delicate balance between immediacy and projection — as in capturing the operator's attention and directing him or her directly to the issue - while ensuring the attention capture isn't in the form of startle inducing cognitive disruption. The latter can prevent the individual from moving beyond the attention capture phase and into the provide information stage required to safely mitigate the situation (Laughery \& Wogalter, 2006; Martin et al., 2012).

There are many ways to measure the metrics of a stall recovery and the effects of a stall warning system on a pilot. Psychophysiological measures can measure startle effect and the aggressiveness of a particular alarm. Behavior and performance measures could detect levels of SA during high periods of activity. Ultimately, with the help of user-centered design, preventative safety measures can help prevent future aircraft accidents. Through design, testing, and documenting, researchers can help provide increased SA during stall warning. 


\section{References}

Aircraft Accident Investigation Bureau (AAIB). (2020). Interim investigation report on accident to the B737-8 (MAX) registered ET-AVJ operated by Ethiopian Airlines on 10 March 2019. Report No. AI-01/19. The Federal Democratic Republic of Ethiopia, Ministry of Transport.

Anderson, J. D. (1999). A history of aerodynamics and its impact on flying machines. Cambridge University, Cambridge, United Kingdom: Cambridge Aerospace Series.

Berka, C., Levendowski, D. J., Lumicao, M. N., Yau, A., Davis, G., Zivkovic, V. T . . Craven, P. L. (2007). EEG correlates of task engagement and mental workload in vigilance, learning, and memory tasks. Aviation Space and Environmental Medicine, 78(5), B231B244.

Breton, R., \& Bossé, É. (2002). The cognitive costs and benefits of automation. Presentation from the NATO Research and Technology, Human Factors and Medicine Symposium. Warsaw, Poland.

Bureau d'Enquêtes et d'Analyses (BEA). (2012). Final report on the incident on 1 June, 2009 to the Airbus A330-203 registered F-GZCP operated by Air France Flight AF 447 Rio de Janeiro-Paris.

Curtis, M. T., Jentsch, F., \& Wise, J. A. (2010). Aviation displays. In E. Salas \& D. Maurino (Eds.). Human factors in aviation (2nd ed.) (pp. 439-478). Burlington, MA: Academic Press. https://doi.org/10.1016/B978-0-12-374518-7.00014-6

Endsley, M. R., \& Jones, D. G. (2004). Designing for situation awareness: An approach to usercentered design (2nd ed.). Boca Raton, FL: CRC Press, Taylor \& Francis Group. 
Freedman, J. (2009). Hijacking the Amygdala. Retrieved from https://web.archive.org/web/20091122194535/http://www.inspirationsunlimited.net:80/images/Hijack.pdf

Federal Aviation Administration (FAA). (2017). Upset prevention and recovery training. Advisory Circular 120-111, Change 1.

Geiselman, E. E., Johnson, C. M., \& Buck, D. R. (2013). Flight deck automation: Invaluable collaborator or insidious enabler? Ergonomics in Design: The Quarterly of Human Factors Applications, 21(3), 22-26. https://doi.org/10.1177/1064804613491268

Glaser, J., \& Tartell, R. (2014). Conversational intelligence at work. OD Practitioner, 46(3), 6267.

Goleman, D. (1995). Emotional intelligence: Why it can matter more than IQ. New York, NY: Bantam Dell.

Goleman, D. (1998). The emotional intelligence of leaders. Leader to Leader, 1998(10), 20-26. https://doi.org/10.1002/lt1.40619981008

Lacagnina, M. (2012). Sustained stall. AeroSafety World. Flight Safety Foundation. Retrieved from http://flightsafety.org/aerosafety-world-magazine/august-2012/sustained-stall

Laughery, K. R., \& Wogalter, M. S. (2006). Designing effective warnings. Reviews of Human Factors and Ergonomics, 2(1), 241-271. https://doi.org/10.1177/1557234X0600200109

Martin, W. L., Murray, P. S., \& Bates, P. R. (2012). The effects of startle on pilots during critical events: A case study analysis. In D. H. Hogreffe (Ed.), Proceedings of the 30th EAAP Conference: Aviation Psychology \& Applied Human Factors - Working towards Zero Accidents (pp. 387-394), Villasimius, Sardinia, Italy, September 24-28, 2012. Retrieved from http://www98.griffith.edu.au/dspace/handle/10072/54072 
Muthard, E. K., \& Wickens, C. D. (2002). Factors that mediate flight plan monitoring and errors in plan revision: An examination of planning under automated conditions Technical Report AFHD-02-11/NASA-02-8. University of Illinois, Institute of Aviation, Savoy, IL.

Pinet, J. (2012). Pilots' operational behavior in unexpected, rapidly evolving situations:

Presentation of a method of analysis cognitive limitations. Cockpit. January - June, 2013. Society of Experimental Test Pilots.

Sherry, L., \& Mauro, R. (2014). Controlled flight into stall (CFIS): Functional complexity failures and automation surprises. Paper presented at the Integrated Communications, Navigation and Surveillance Conference (ICNS), Herndon, VA, April 8-10, 2014. https://doi.org/10.1109/ICNSurv.2014.6819980

Stall Warning. (2014). 14 Code of Federal Regulations $§ 25.207$.

Wickens, C. D. (2000). The trade-off of design for routine and unexpected performance: Implications of situation awareness. In M. R. Endsley \& D. J. Garland (Eds.), Situation awareness analysis and measurement (pp. 211-225). Mahwah, NJ: Erlbaum.

Wickens, C. D. (2002). Situation awareness and workload in aviation. Current Directions in Psychological Science, 11(4), 128-133. doi:10.1111/1467-8721.00184 